\title{
Intraosseous lipoma of the rib
}

\author{
Atilla Eroglu, MD, ${ }^{a}$ Cemal Gundogdu, MD, ${ }^{b}$ Atila Turkyilmaz, $\mathrm{MD}^{\mathrm{a}}$ and Nurettin Karaoglanoglu, $\mathrm{MD},{ }^{a}$ Erzurum, Turkey
}

A lthough lipoma is the most common tumor of the body, intraosseous location is rare. Intraosseous lipomas are benign bone tumors composed of mature adipocytes. They represent $0.08 \%$ of all primary bone tumors and are usually asymptomatic, with the diagnosis being made incidentally. Most involve long bones, especially in the lower extremities. Intraosseous lipoma of the rib is an extremely uncommon benign tumor, only two cases having been published in the literature. We report an unusual case of intraosseous lipoma arising from the left sixth rib and briefly review the literature.

\section{Clinical Summary}

A 21-year-old man had a 5-month history of left-sided chest pain. On physical examination, a non-tender ill-defined hard mass was palpable overlying the left sixth to seventh ribs. Plain radiograph of the chest revealed a large expansive lytic destructive lesion arising from the posterior end of left sixth rib. Computed tomographic (CT) scan revealed a well-defined localized expansive mass having a soft tissue center and internal thick septations (Figure 1). The lesion had a large intrathoracic component and small extrathoracic component. On the basis of imaging findings, differential diagnoses of giant cell tumor, plasmacytoma. and less likely aneurysmal bone cyst were entertained. The patient underwent uniblock wide surgical resection of the left sixth and seventh ribs and intercostal muscles. Macroscopically, the tumor measured $5.0 \times 2.5 \times 2.0 \mathrm{~cm}$ and bulged from the inner surface of the seventh rib toward the thoracic cavity. The irregular tumor was covered with normal pleura. Microscopically, the lesion was circumscribed by a thin fibrous capsule and mainly constituted by mature adipose tissue. Adipocytes were benign without evidence of atypias or pleomorphism, and mitosis or necrosis was not appreciated (Figure 2). The pathologic findings were compatible with an intraosseous lipoma of the rib.

The patient had an uneventful postoperative course and was discharged on the seventh postoperative day. He has been followed up for 2 years without evidence of recurrence.

\footnotetext{
From the Departments of Thoracic Surgery, ${ }^{\mathrm{a}}$ and Pathology, ${ }^{\mathrm{b}}$ Ataturk University, School of Medicine, Erzurum, Turkey.

Received for publication June 28, 2005; accepted for publication July 19, 2005.

Address for reprints: Atilla Eroglu, MD, Ataturk University, Medical Faculty, Department of Thoracic Surgery, Erzurum, Turkey (E-mail: aeroglu@atauni.edu.tr, atilaeroglu@hotmail.com).

J Thorac Cardiovasc Surg 2005;130:1468-9

$0022-5223 / \$ 30.00$

Copyright (C) 2005 by The American Association for Thoracic Surgery doi:10.1016/j.jtcvs.2005.07.016
}

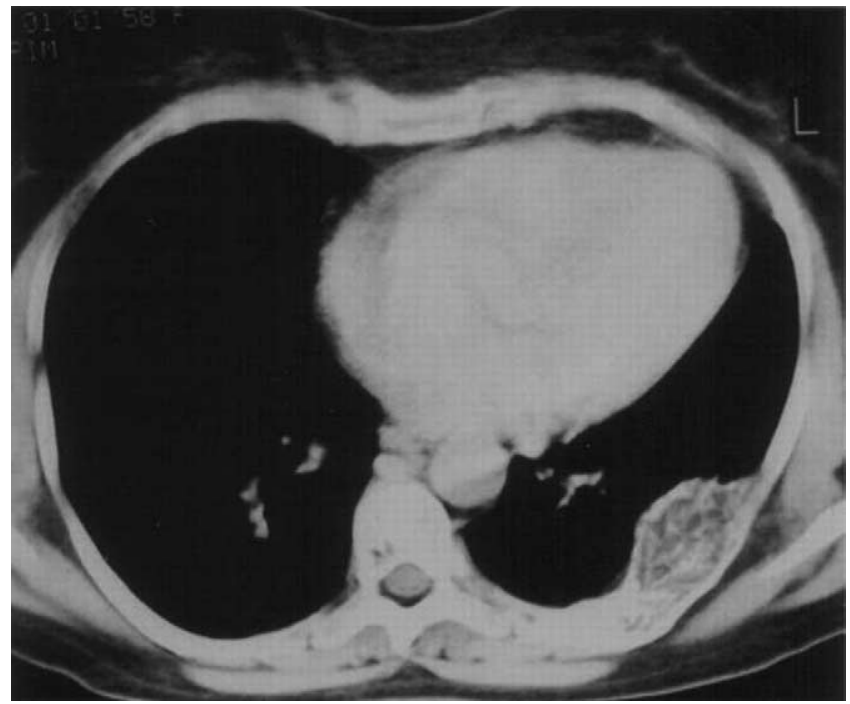

Figure 1. Axial contrast-enhanced CT showing a well-defined, destructive lesion having a soft tissue center of cortical bone arising from the posterior end of the left sixth rib.

\section{Discussion}

Intraosseous lipoma was first reported by Wehrsig ${ }^{1}$ in 1910 , who described a case of intraosseous lipoma of the proximal fibula in a 5-year-old girl. Although bone marrow contains abundant adipose tissue, intraosseous lipomas are rare. Because the intraosseous

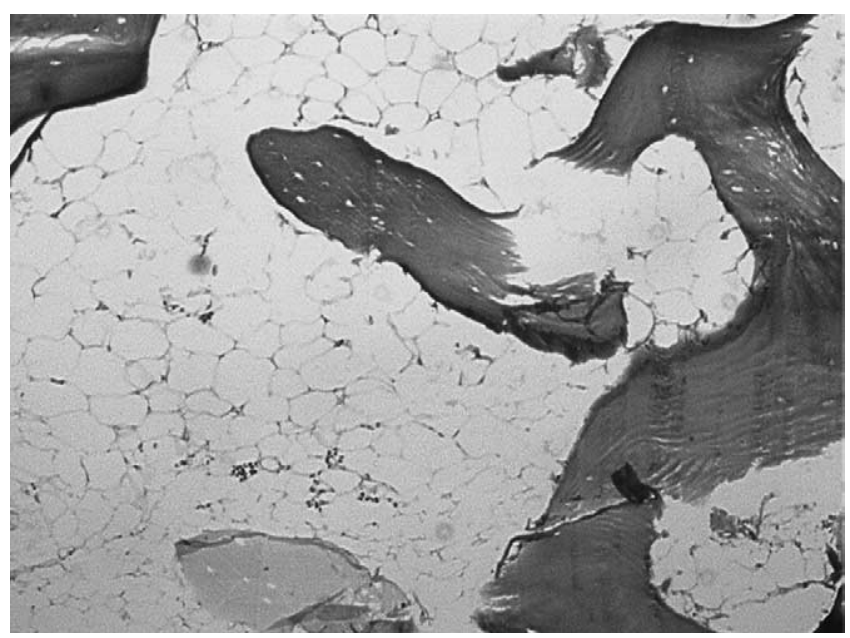

Figure 2. Histopathologic specimen showing mature adipose tissue containing areas of bone differentiation (hematoxylin and eosin $\times 100$ ). 
lipoma may be asymptomatic and is frequently misdiagnosed, it is thought to be more common than the literature reports. They are uncommon tumors, representing $0.08 \%$ of all primary bone tumors, and are usually asymptomatic, the diagnosis being made incidentally. ${ }^{2}$ Their etiology is unclear. The natural history includes a tendency to spontaneous involution through a process of infarction, calcification, and cyst formation. Although intraosseous lipomas are generally considered benign bone neoplasms, malignant transformation has rarely been described. In 1988 Milgram $^{3}$ reported the clinical, radiologic and histologic features of intraosseous lipoma in 66 cases. The sites of involvement were widespread throughout the axial and appendicular skeleton, with a predilection for the proximal femur (35\%), the tibia and fibula $(21 \%)$, calcaneus $(8 \%)$, and ilium (8\%). Intraosseous lipoma of the rib is an extremely uncommon benign tumor, with only two cases having been published in the literature., ${ }^{4,5}$

Various kinds of radiologic examinations are useful in diagnosing these tumors. On plain radiographs, the tumor appears as a well-circumscribed radiolucent lesion that is often surrounded by thin, well-defined sclerotic borders. The radiographic differential diagnosis includes bone infarct, solitary bone cyst, nonossifying fibroma, fibrous dysplasia, giant cell tumor of the bone, aneurysmal bone cyst, osteoblastoma, and chondroblastoma. It is difficult to establish the diagnosis of intraosseous lipoma lacking calcification or ossification only with plain radiographs. However, CT tomography or magnetic resonance imaging alone can almost establish the diagnosis, because the tumor consists of adipose tissue. On CT scan, an intraosseous lipoma usually looks like a well-defined mass almost entirely composed of mature adipose tissue, with an osseous excrescence within it and/or erosion at the attachment of the soft tissue mass to the subjacent cortex. As in the case presented, axial CT images are useful to define the relationship of the mass with the adjacent organs and can help to exclude a malignant process.

Histologically, intraosseous lipomas are composed of mature adipose tissue cells similar to those of soft tissue lipomas. In intraosseous lipomas, foci of calcification or ossification are seen microscopically, as well as on plain radiographs. In many cases, wide excision is necessary to provide adequate tissue for exact histologic diagnosis. Surgical resection of the affected rib is the treatment of choice for lipoma of the rib. Because more than half of all primary rib tumors are malignant, prompt investigation, accurate tissue diagnosis, and usually generous surgical excision are required. After wide surgical resection of the mass, our patient had an uneventful postoperative course with no evidence of local recurrence 2 years after surgery.

Intraosseous lipoma of the rib is an extremely uncommon tumor that has been found incidentally. It should be considered in the differential diagnosis of rib tumors, especially in asymptomatic patients.

\section{References}

1. Wehrsig G. Lipom des Knochenmarks. Z Allg Pathol. 1910;21:243-7.

2. Unni KK, editor. Dahlin's bone tumors: general aspects and data on 11,087 cases. 5th ed. New York: Lippencott-Raven; 1996. p. 349.

3. Milgram JW. Intraosseous lipomas: a clinicopathologic study of 66 cases. Clin Orthop Relat Res. 1988;231:277-302.

4. Fiorentino L, Rossi G, Ruggiero C, Valli R, Gusolfino D, Massimiano $\mathrm{M}$, et al. Parosteal lipoma of the rib: report of a case. Pathologica. 2001;93:668-71.

5. Imbriaco M, Ignarra R, De Rosa N, Lambiase G, Romano M, Ragozzino A. Parosteal lipoma of the rib: CT findings and pathologic correlation. Clin Imaging. 2003;27:435-7. 